\author{
International Journal of Innovative Research in \\ Electrical, Electronics, Instrumentation and Control Engineering
}

Vol. 9, Issue 10, October 2021

DOI: $10.17148 /$ IJIREEICE.2021.91017

\title{
Design and simulation of Three phase to Three phase Matrix Voltage Converter under Unbalanced Supply
}

\author{
Mr.Chandan Kumar ${ }^{1}$, Dr.Shafali Jain ${ }^{2}$, Mr Mithlesh Gautam ${ }^{3}$ \\ ${ }^{1}$ M.Tech*- Power Electronics, Truba College of Science and Technology, Bhopal, M.P \\ ${ }^{2}$ Professor\& Head, Dept of Electrical \& Electronics Engg, TIEIT, Bhopal, M.P \\ ${ }^{3}$ Assistant Professor, Dept of Electrical \& Electronics Engg, TCST, Bhopal, M.P
}

\begin{abstract}
This paper presents a new control method for indirect matrix converter operating under unbalanced supply voltages. The proposed method aims to achieve balanced output voltages as well as a near unity input power factor operation. A Feed-Forward compensation method is used to get the balanced output voltage under unbalance supply voltages. A virtual dc - link voltage is generated by the use of voltage source rectifier then depending on the virtual dc link voltage the modulation index of the inverter is adjusted to get the balanced desired magnitude output voltage. A proportional resonant controller is designed in dq reference frame to calculate the input power factor angle at the matrix converter input for the unity power factor operation of matrix converter system including the input current filter under unbalanced grid voltages. The effectiveness of control method to get the balanced output voltage and unity power factor operation of matrix converter system under unbalanced grid voltage, is verified through simulation study.
\end{abstract}

Index Terms: Active rectifier, matrix converters, power factor correction, resonant controllers, space vector modulation (SVPWM), unbalanced grid voltages.

\section{INTRODUCTION}

Power frequency converter is an essential component in ac drive applications. From power quality point of view, it is desirable that the frequency changer must provide sinusoidal output voltages with varying amplitude and frequency, while drawing sinusoidal input currents with controllable displacement factor preferably unity from the ac source. The matrix converter offers a near ideal solution for AC-AC power conversion, removing the need for reactive energy storage components used in conventional rectifier-inverter based systems [1].

Basically, the matrix converter is nothing but a three-phase to three-phase forced commutated cyclo-converter. The matrix converter topology was originally presented in 1976 by Gyugyi-Pelly [1] but it was in 1980 that the basic configuration and control of three-phase matrix converter were introduced by Venturini in [2] [3].

A three phase to three phase matrix converter consists of nine bidirectional switches which are arranged in such a way that any of the input phases can be connected directly to the any of the output phases of the converter following a particular modulation of the duty cycles of the switches. The arrangement of the switches is illustrated in Fig.1. 


\section{International Journal of Innovative Research in \\ Electrical, Electronics, Instrumentation and Control Engineering}

Vol. 9, Issue 10, October 2021

\section{DOI: 10.17148/IJIREEICE.2021.91017}

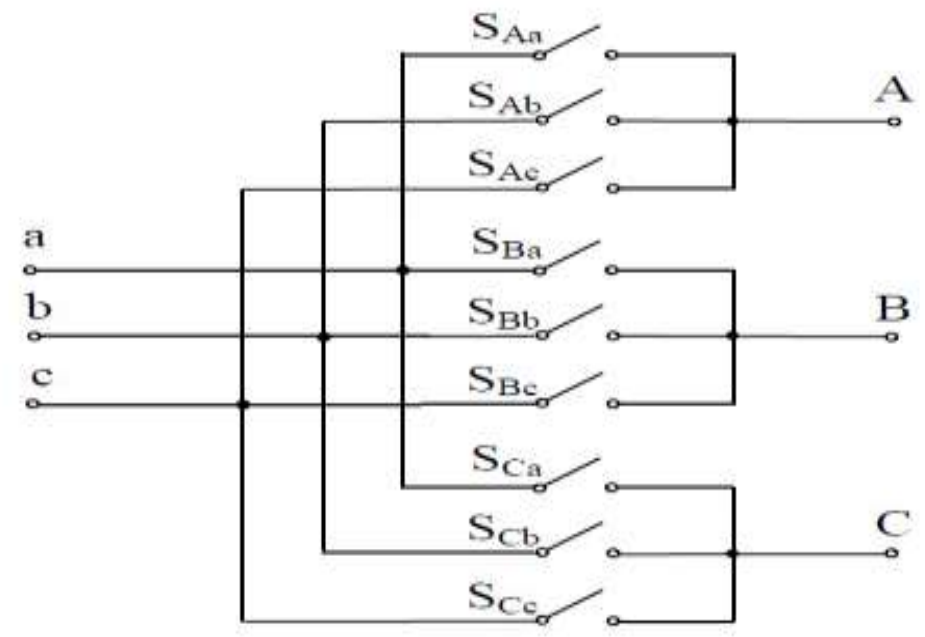

Figure 1: Schematic circuit of a three-phase to three-phase matrix converter [5]

\section{EFFECT OF INPUT UNBALANCED VOLTAGE ON MATRIX CONVERTER PERFORMANCE}

A three phase to three phase matrix converter, consists of nine bidirectional switches which are arranged in such a way that any of the input phases can be connected directly to the any of the output phases of the converter, following a particular modulation of the duty cycles of the switches. The arrangement of the switches is illustrated in Fig. 2.

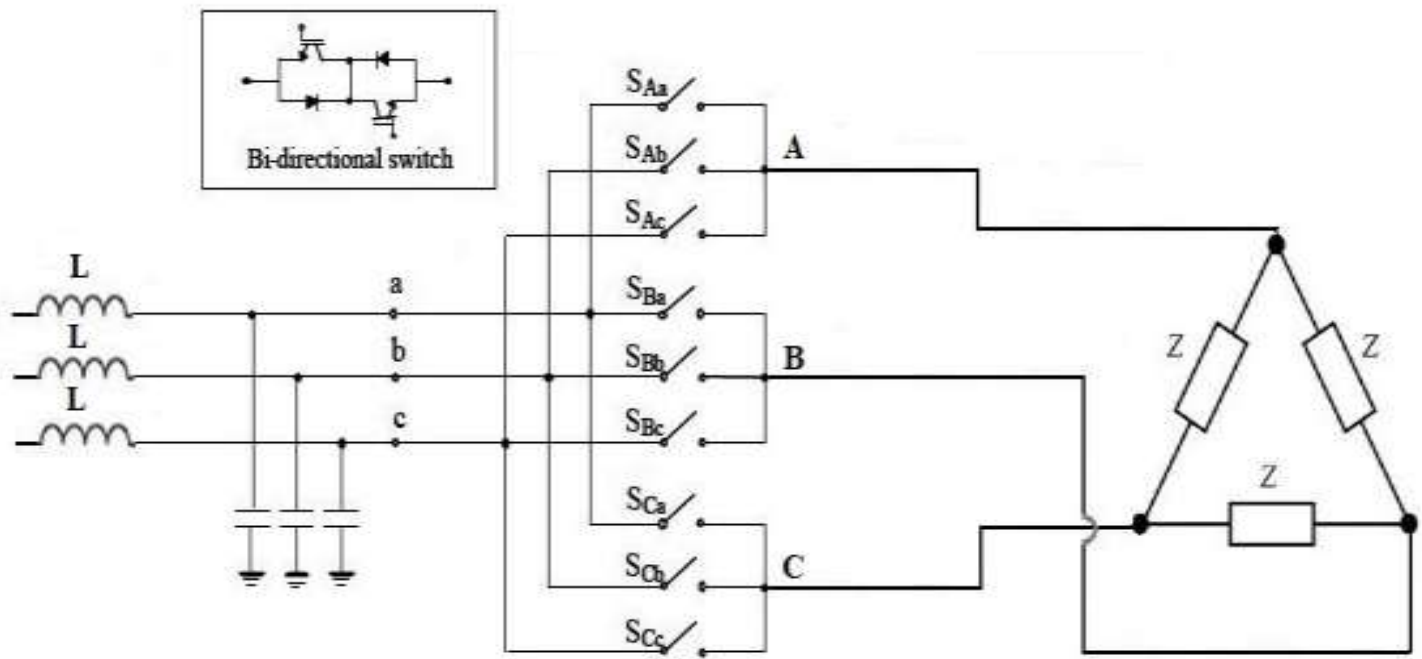

Figure 2: Three-phase to Three-phase matrix converter

However, because matrix converter is a direct frequency conversion device without any energy storage components, the load side of it can be seriously affected by the distorted or unbalanced input voltages which can result in unwanted loworder harmonics in the input current and output voltages. These abnormal input behaviours deteriorate the working performances of the load.A phase shift is introduced between line currents and grid voltages due to the presence of input LC filter between grid and matrix converter, by which power factor decreases [12], [13]. As the power factor at the grid side decreases due to the presence of input LC fillter then the reactive power demand from the grid increases which causes increase in distribution and transmission power losses. Hence, the most appropriate operating mode for matrix converter is the unity input power factor operation

To improve the performance of direct or indirect matrix converter operating under unbalanced grid voltages, several methods were proposed in the literatures. In [17], a modulation technique is introduced to eliminate the input current distortion due to unbalanced grid voltage. In [18], a modified space vector modulation strategy is introduced for the matrix converter operating under unbalanced grid voltage. By using the the instantaneous magnitude and phase angle of 


\section{International Journal of Innovative Research in \\ Electrical, Electronics, Instrumentation and Control Engineering}

Vol. 9, Issue 10, October 2021

\section{DOI: 10.17148/IJIREEICE.2021.91017}

input voltage space vector, modulation index is recalculated which can give balanced output voltage. In [19], three modulation strategies for matrix converter based on mathematical construction are proposed under unbalanced grid voltage. These three modulation strategies are developed based on the construction of the rectifier and inverter modulation vectors in three different ways. In [20], a feed-forward compensation technique is proposed to prevent the input voltage harmonics from propagating onto its output characteristics. In [21], a pridictive control technique is proposed to control the input and output variables. Several methods are also proposed in the literatures to get the unity power factor operation of matrix converter system under balanced grid voltages [12], [13].

A control method is proposed by Mahmoud Hamouds's paper [23] for the indirect matrix converter operating under unbalanced grid voltage. The main aim of the proposed control method are:

Output voltage of the converter should be balanced under unbalanced grid voltage.

Grid side power factor should be unity under balanced or unbalanced grid voltage.

Voltage unbalance in AC mains having finite input impedance arises from numerous unsymmetrical conditions, such as unbalanced three phase loads connected on the lines, transmission line impedance or large single phase loads. Although the unbalance magnitudes are usually very small, they can develop serious power quality issues [23].

To control the matrix converter, indirect transfer function approach is used. Indirect Transfer Function approach (ITF) is considered as two steps of input voltage processing. In the first step, three phase input supply voltages are multiplied with a PWM switching function of the rectifier " to yield a fictitious dc link. In the second step, the fictitious dc link is multiplied by a PWM switching function of the inverter " to yield the final three phase sinusoidal output voltages.

\section{SIMULATION RESULT AND DISCUSSION}

For the evaluation of the performance of control methodology a MATLAB- simulink model of a matrix converter connected to unbalanced three-phase voltage sources and feeding a three-phase delta connected RL-load is built.

Table.1: Parameter Settings

\begin{tabular}{|l|l|}
\hline Parameter & Value \\
\hline Supply line voltage & $230 \mathrm{~V}$ \\
\hline Source frequency & $50 \mathrm{~Hz}$ \\
\hline Voltage Transfer ratio & 0.8 \\
\hline Load frequency & $50 \mathrm{~Hz}$ \\
\hline Input filter capacitance & $21.5 \mu \mathrm{F}$ \\
\hline Input filter inductance & $4 \mathrm{mH}$ \\
\hline Input filter resistance & $0.5 \Omega$ \\
\hline Load inductance & $8 \mathrm{Mh}$ \\
\hline Load resistance & $10 \Omega$ \\
\hline Sampling period & $200 \mu \mathrm{s}$ \\
\hline
\end{tabular}

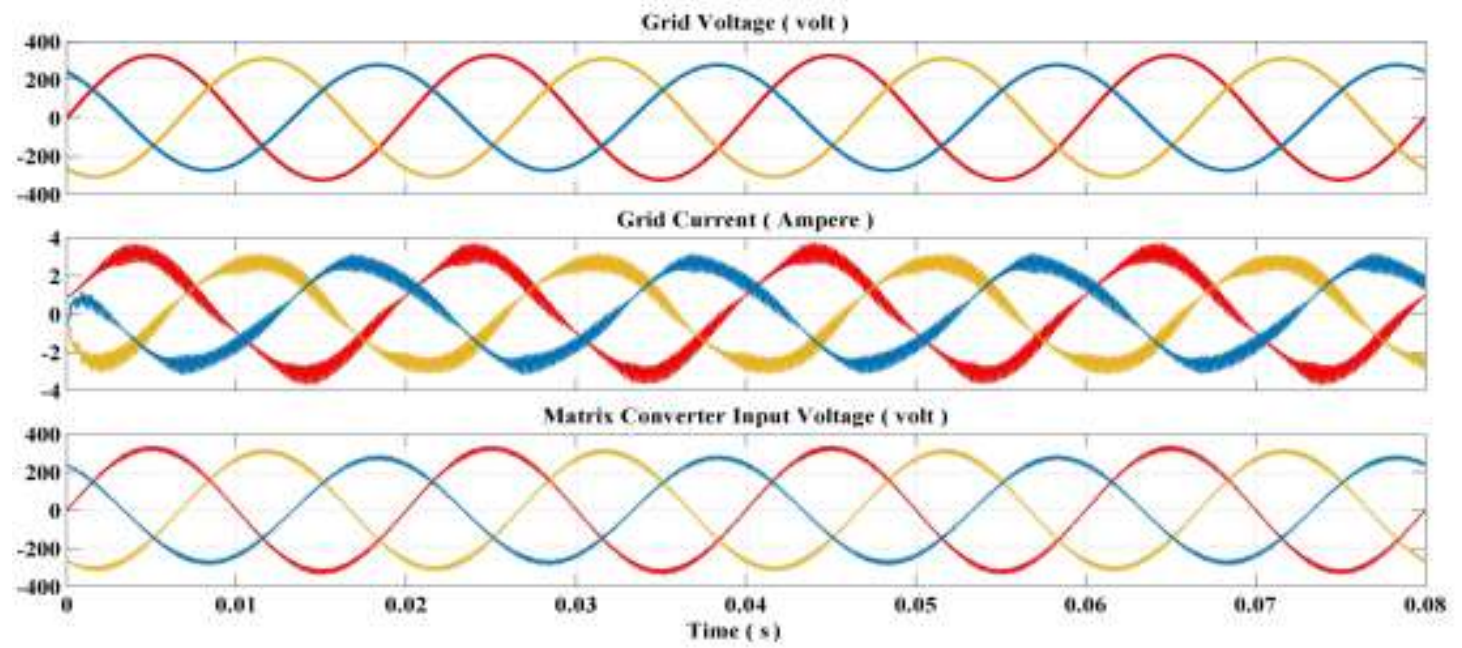

Figure 3: Waveforms of magnitude unbalanced three-phase grid voltages, Grid phase current and Matrix converter input phase voltages 
International Journal of Innovative Research in Electrical, Electronics, Instrumentation and Control Engineering

Vol. 9, Issue 10, October 2021

DOI: 10.17148/IJIREEICE.2021.91017

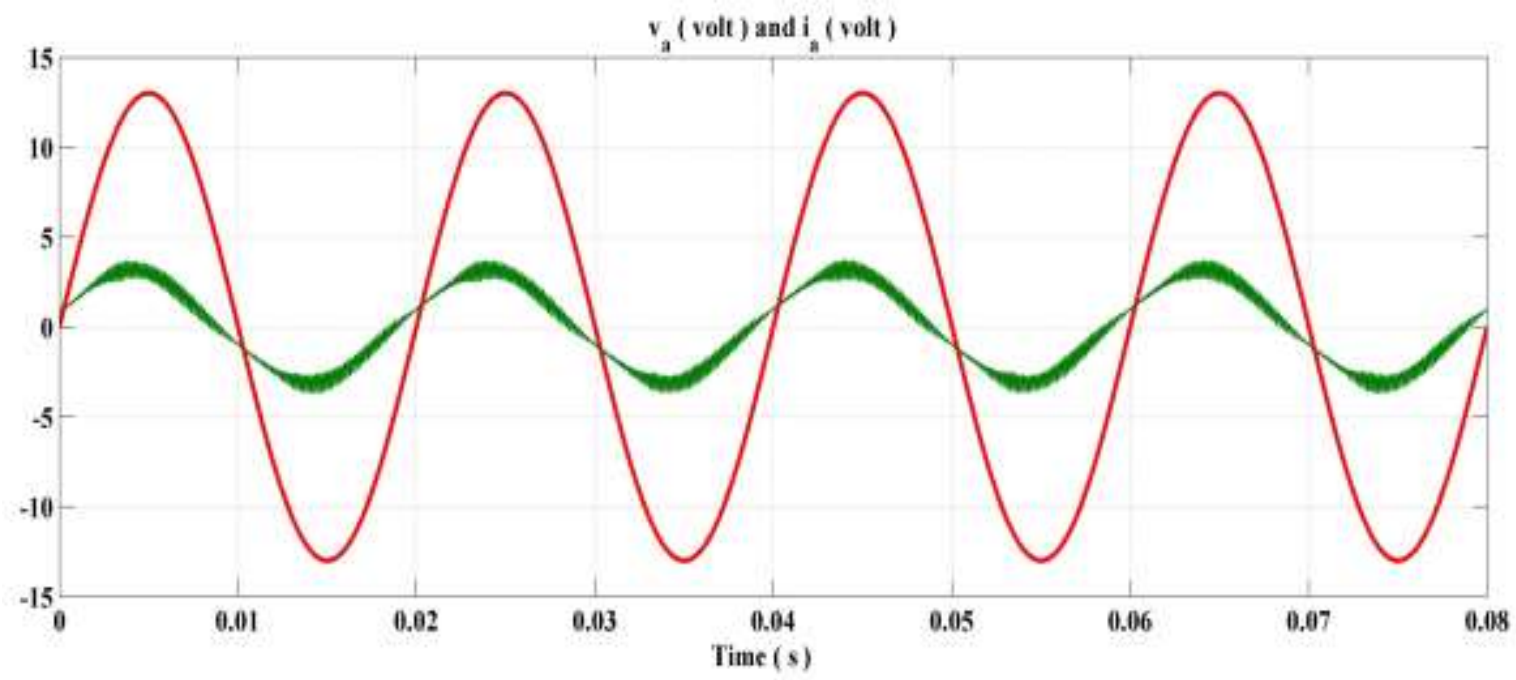

Figure 4: Waveforms of a - phase scaled grid voltage (va) and current (ia) under magnitude unbalanced three phase grid voltage

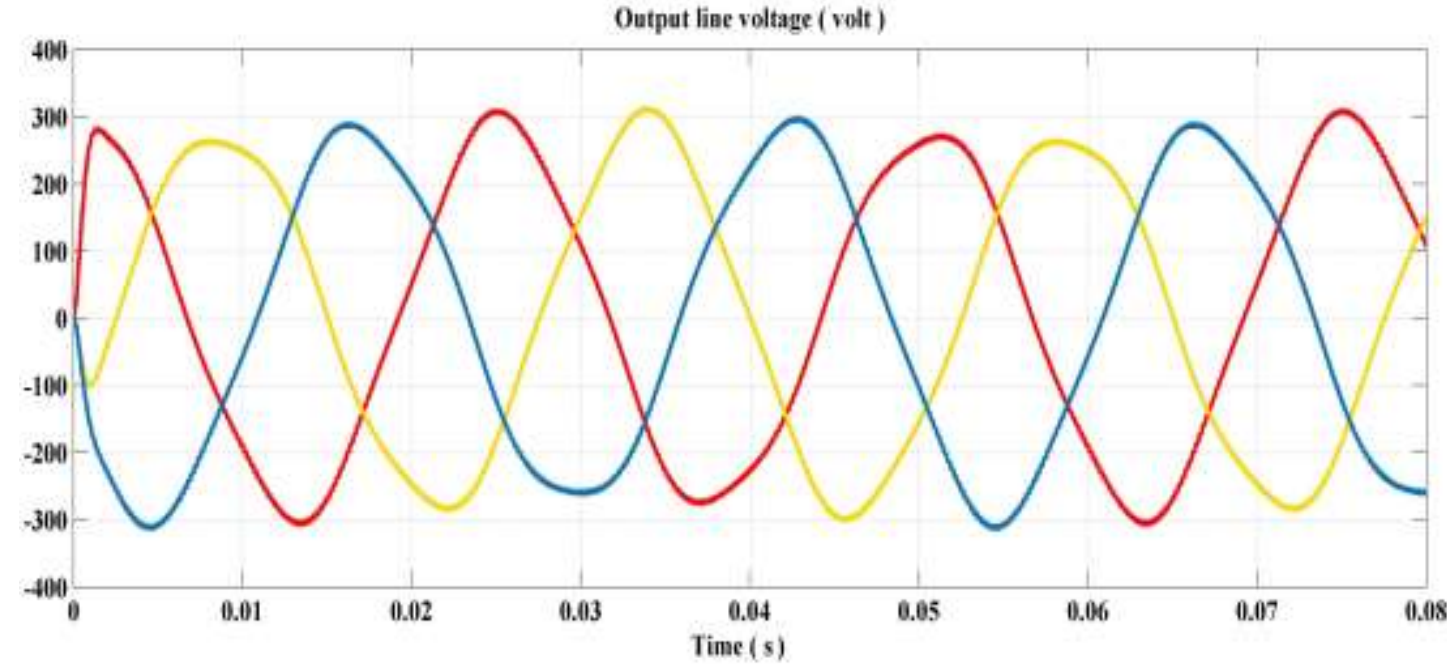

Figure 5: Filtered output line voltage of the matrix converter under magnitude unbalanced three - phase grid voltage

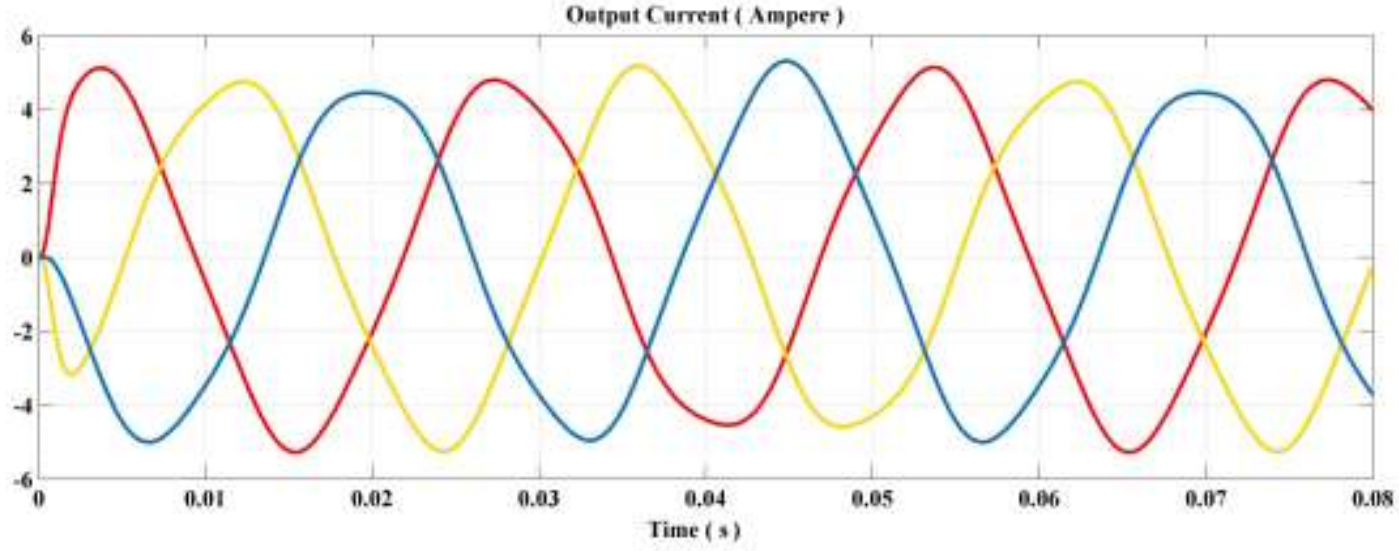

Figure 6: Filtered output line current of the matrix converter under magnitude unbalanced three - phase grid voltage 


\title{
International Journal of Innovative Research in \\ Electrical, Electronics, Instrumentation and Control Engineering
}

\author{
Vol. 9, Issue 10, October 2021
}

\section{DOI: 10.17148/IJIREEICE.2021.91017}

By observing above simulation results under magnitude unbalanced grid voltages, it can be concluded that the output voltage and current of the MC system are not balanced as shown in Fig.5 and Fig.6, due to the presence of low-order harmonics. An inherent phase shift is introduced between line currents and grid voltages as shown in Fig.4, due to the presence of LC filter between grid and the MC, due to which MC system is not operating at unity power factor

\section{IV.CONCLUSION}

The control method proposed in this paper is a very effective solution to remove the problems which occurred in the matrix converter when it is connected to the magnitude unbalanced grid supply. This method provide approximately balanced output voltages and achieve a near unity power factor operation of matrix converter under unbalanced grid voltage. The simulation results showed that by the use of this control topology we achieved balanced output voltage and near unity power factor operation of matrix converter under magnitude unbalanced grid voltage. The control topology is also simulated for the performance of the whole system when sudden change in the magnitude unbalanced grid supply occurs, which shows that the control topology gives good results under this condition also. The system becomes balanced in approximately $5 \mathrm{~ms}$ after the sudden change in the input supply.

\section{REFERENCES}

[1] Venturini M, "A new sine wave in sine wave out, conversion technique which eliminates reactive elements", in Proc. POWERCON7, pp. E3_1E3_15, 1980.

[2] G Roy and G.E.April, "Cycloconverter operation Under a new scalar control Algorithm" 20th Annual IEEE Power Electronics Specialists Conference,pp.368-375, 1989.

[3] L Huber and D Borojevic, "Space Vector For Force Commutated Cycloconverter", IEEE IAS Annual Meeting, pp.871-876, 1989

[4] Donato Vinecenti and Hua Jin "A three- phase regulated PWM rectifier with On-line Feedforward input unbalance Correction" IEEE Trans. Ind. Electron Vol.41.No.5,pp.326-532,October1994.

[5] L. Huber and D. Borojevic, "Space vector modulated Three-Phase to Three-Phase Matrix Converter with Input Power Factor Correction". IEEE Trans. Ind. Application. vol. 31, pp. 1234-1246, Nov. / Dec. 1995.

[6] D. Casadei, G. Serra, and A. Tani, "Reduction of the input current harmonic content in matrix converters with input power factor correction ", IEEE Trans. Ind.App. ElectronVol. 31, pp. 1234-1246,Nov-Dec, 1995.

[7] P. Nielsen, F. Blaabjerg, and J. K. Pedersen, Space vector modulated matrix converter with minimized number of switching and feedforward compensation of input voltage unbalance, in Proc. Power Electron. Drives Energy Syst., pp. 833839. 1996.

[8] L.Huber, and DusanBorojevic "Space vector modulated three-phase to three phase matrix converter with minimized number of switching and feedforward compensation of input voltage unbalance, in Proc. Power Electron. Drives Energy Syst., pp. 833839. 1996.

[9] D. Casadei, G. Serra, and A. Tani, "Reduction of the input current harmonic content in matrix converters under input/output unbalance ", IEEE Trans. Ind.App. Electron vol. 45, pp. 401-411,june, 1998.

[10] Ana Vladan Stankovic, Thomas A Lipo, " A novel control method for input output harmonic elimination of the PWM boost type rectifier under unbalanced operating conditions", IEEE Trans. on Power Electronics, Vol. 16, No. 5, pp. 603-61 1. 2001.

[11] F Blaabjerg,DCasadei,CKlumpner and M Matteini "Comparison of two current modulation strategies for matrix converter under unbalanced input voltage conditions”,IEEETrans.on Industrial Electronics, Vol. 49, No. 2, pp. 289-296. 2002.

[12] Patrick W. Wheeler, Jose Rodriguez, Jon C. Clare and Lee Empringham, "MatrixConverters: A Technology Review", IEEE Trans. Ind. Electron.,Vol. 49, No.2, pp.276-288, April,2002.

[13] L.Wei, Y. Matsushita, and T. A. Lipo, "Investigation of dual-bridge matrix converter operation under unbalanced source voltages", in Proc. IEEE Power Electron. Spec.Conf., pp. 12931298. 2003.

[14] Yang Mei, Kai Sun, Daning Zhou, Lipei Huang "Analysis and Compensation of Matrix Converter Operation Under Abnormal Input Voltag Conditions"Conditians.Proc. of ICEMS 2004, Beijing, China,: V01.-1 pp.402-406,2004.

[15] Y. Suh and T. A. Lipo, "Modeling and analysis of instantaneous active and reactive power for PWM AC/DC converter under generalized unbalanced network," IEEE Trans. Power Del., vol. 21, no. 3, pp. 1530-1540, Jul.2006.

[16] M Jussila and H Tuusa "Comparision of simple control strategies of space-vector modulated indirect matrix converter under distorted supply voltage" IEEE Trans.power Electronics,vol.22.no.1 January 2007.

[17]I sato,J Itoh,H ohguchi,A odaka and H Mne "An Improvement method of matrixconverter drives under input voltage disturbances" IEEE Trans.on power Electronics,vol.22.no.1 January 2007.

[18] J. Hu, Y. He, L. Xu, and B. W. Williams, "Improved control of DFIG systems during network unbalance using PI-R current regulators," IEEE Trans. Ind. Electron.,vol.56 no. 2, pp. 439-451, Feb. 2009.

[19] A. G. Yepes, F. D. Freijedo, J. Doval-Gandoy, O. Lopez, J. Malvar, and P. Fernandez Comesana, "Effect of discretization methods on the performance of resonant controllers," IEEE Trans. Power Electron., vol. 25, no. 7, pp. 1692-1712, Jul. 2010.

[20] M Hamouda,H Fortin Blanchette ,K Al-Hsdded and F Fnaiech "An Efficient DSP- FPGA-Based Real-Time Implementation Method of SVM Algorithms for an Indirect Matrix Converter” IEEE Trans. Ind. Electron., vol. 58, no. 11, pp. 5024-5031, Nov. 2011.

[21] X wang,H lin,H she and B Feng "A Research on Space vector modulation Strategy for Matrix converter under abnormal input voltage conditions" IEEE Trans.on Industrial Electronics,vol.59.no.1 January 2012.

[22] A. Vidal, F. D. Freijedo, A. G. Yepes, P. Fernandez-Comesana, J. Malvar, O. Lopez and J.Doval-Gandoy, "Assessment and optimization of the transient response of proportional-resonant current controllers for distributed power generation systems,'IEEE Trans. Ind. Electron., vol. 60, no. 4, pp. 1367-1383, Apr. 2013.

[23] M. F. Iacchetti, G. D. Marques, and R. Perini, "Torque ripple reduction in a DFIG-DC system by resonant current controllers," IEEE Trans. Power Electron., vol. 30, no. 8, pp. 4244-4254, Aug. 2015.

[24] M Hamouda,H Fortin Blanchette and K Al-Hsdded "Unity Power Factor Operation of Indirect Matrix Converter Tied to Unbalanced Grid" IEEE Trans. Power Electron.,. 31, no. 2, pp. 1095-1107, February 2016. 